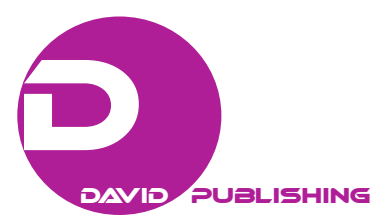

\title{
Balancing Between the New Family Law and Religious Practices and Its Impact on Moroccan Women's Lives
}

\author{
Souad SLAOUI \\ idi Mohammed Ben Abdellah University, Fez, Morocco
}

\begin{abstract}
The present paper seeks to shed light on the main factors lying behind the non-implementation of Article 20 of the New Moroccan Family Law reformed in 2004 which is concerned with legal minimum age of marriage for both sexes, 18 years old for both. This study aims at investigating why the number of marriages of young girls continue to increase despite the establishment of the Law. The author takes the region of Fez as a case in point to explore this social behavior in Moroccan society. A qualitative approach has been adopted by interviewing 10 persons including Family Affairs Judges, lawyers and University Professors of Islamic studies at the University of Fez. Added to this, the technique of observation has equally been utilized to have everyday life concrete experiences of young girls "marriages". It has been argued that a unilateral approach to this social phenomenon cannot succeed to understand the complex nature of this bad social habit that is still predominant among rural areas and marginalized urban districts. A rather global approach taking into account the economic, socio-cultural, and legal dimension of the issue under investigation proves to be much more adequate to explore the intricate nature of this problems in which a number of diverse variables interact. The paper ends up with a conclusion and a number of recommendations on how to reduce this social act.
\end{abstract}

Keywords: early marriage, Article 20 of the New Family code, poor-economic infrastructure, socio-cultural norms-establishment of the law

\section{Introduction}

Following its independence from French colonial rule in 1956, Morocco initially adopted a socially conservative policy towards family law by promulgating the Muddawwana or Code of Personal Status of 1957-58. The Muddawwana was essentially a reiteration of the Maliki family law left in place during French colonization. It was first formulated as a set of royal decrees released between 1957 and 1958. Under the Muddawwana of the 1950s, a woman was a minor under the guardianship of her father, husband, or other male guardian. Minor revisions were made to the Mudawwana by royal decree in 1993, but the spirit of the law remained essentially intact. The amendment did not introduce any significant changes that surrounded the family law, but it was still a major breakthrough for feminist movement.

In January 2004, the New Family code was announced in the official bulletin. It is based on two references: Shari'a (the Muslim law) and the International law agreements. This new Family code is designed around three axes: (1) Equality between spouses; (2) Family equilibrium; and (3) The protection of children. As to the first item (equality between spouses): the legal age of marriage is fixed at 18 for both sexes, both spouses are legally 
heads of the family. Spouses have equal rights and duties. Women who are over 18 do not need a tutor before contracting marriage. The New Family Law also concerned itself with the family equilibrium; hence, the following amendments are introduced: The public ministry automatically intervenes in any application of the family law, and the family courts are for the first time established.

The main contributions Moroccan women's movement has been to raise women's awareness of their rights, We will focus on this issue through an interesting question concerning the item of the legal age of marriage that is currently fixed under the new reform of the Moudawwana at 18 years for both sexes. The aim is to show how this phenomenon can be used to justify the non-implementation of the New Family code. We equally seek to explain how Moroccan selective mentality in balancing between the law and religious practices can negatively affect the life of women. In this respect, consider Article 20, which clearly states that:

The Family Affairs Judge in charge of marriage may authorize the marriage of a girl or boy below the legal age of marriage as stipulated in preceding article 19, in a well-substantiated decision explaining the interest and reasons justifying the marriage, after having heard the parents of the minor who has not yet reached the age of capacity or his/her legal tutor, with the assistance of medical expertise or after having conducted a social enquiry.

With this background in mind, the present paper addresses the following research questions:

(1) To what extent has the New Family Code, and more specifically, article 20 which is concerned with the legal age of marriage to 18 year old for both sexes, reduced the rate of early marriage of girls in the Moroccan society?

(2) To what extent do the economic and socio-cultural variables put pressure on this social behavior and contribute into the continuation of this social phenomenon despite the establishment of the law?

\section{Methodology}

\section{Review of the Literature}

The issue of early marriage has been the subject matter of a large number of studies carried out within the new changes of the New Family Code. It has occupied a predominant position among researchers each one according to her/his field of interest. Most of those studies vary from sociological, cultural, legislative, judiciary etc. which has ended up to the emergence of a number perspectives and rich approaches. Their interest in the topic follows from the complexity and intricacy of this subject in which a number of factors responsible for it intersect and interact with each other. Viewed from a sociological point of view, Sadiqi (2008) attributes the dominance of such a behavior among Moroccan families to the societal pressure on individuals. The same view is equally shared by Charrad (2012) in her study about Moroccan and Tunisian societies. Ennaji (2011) rightly observed that the non-implementation of the New Family Law is observed through the fact that early marriage is still practiced. He further noted that this rise in early marriage is due to the return to conservative thought in legal reform. Kerkech (2013) equally confirmed this view by stating that generally speaking, social cultural and psychological factors significantly impact women's life and status even more than legal factors in Morocco. As to Hanafi (2013), whose research focuses on women's rights to have access to justice within the new family law, she highlighted the social and institutional obstacles that stand against women's rights as given to her by the law. She addressed many legislative, judicial and institutional amendments that have been achieved by this new version of the family code drawing attention to the difference between the rural and urban women, where the phenomenon of early marriage is still predominant. She found out that there is a discrepancy between urban and rural women as far as their awareness of the rights that the 
new Family Law provide for them as well as their access to justice. Despite the fact that the New Family emphasizes on equality between the two categories of women, rural women's access to justice remains limited if compared to women in urban areas.

\section{Research Hypotheses}

To achieve the purposes of this research, we have formulated two hypotheses on the basis of the early marriage literature and the different literature done in different contexts:

Hypothesis 1: Despite the legal nature of the New family Code and more particularly Article 20 which states that the legal age of marriage is 18 year old for both girls and boys, this law cannot control this phenomenon.

Hypothesis 2: The economic and socio-cultural constraints contribute in consolidating the phenomenon of early marriage in the Moroccan society (viz. in rural areas), which makes this phenomenon fugitive.

\section{Justification for the Choice of the Sample}

This study adopts a qualitative method of research as well as the observation technique for data collection.

We have based this study on in-depth interviews with 10 different individuals specialized in various domains: 2 Family Affairs judges (one working in the Family Court of Fez and the other one who worked as judge for few years in Fez and has just moved to work in Rachidiyya); 6 lawyers; 2 university Professors at the Islamic Studies Department at the Faculty of Letters Dhar El Mehraz, Fez. Most importantly, the author attended two morning sessions witnessing the 37 cases of interviews the Family Affairs Judge at the court of Fez had with the minor girls and their parents who had already submitted their demands to have the judge authorizing them this marriage, and had the interview meeting with the Family judge to either approve or refute the marriage demand file .

\section{Approach}

This paper is embedded within sociological studies adopting the Gender approach which is a social variable that becomes a predominant issue in research on social and legal changes. Indeed, early marriage is considered as one of the social phenomena that can be explored from a gender perspective and that can be of the most outstanding perspectives that can help explaining and understanding the underlying reasons behind this complex social behavior in Morocco where a number of legal, socio-cultural and economic intricately intersect with each other.

\section{Data Analysis and Interpretation}

\section{Early Marriage as Evidence for the Non-implementation of the New Family Code}

From the interviews conducted, we came out to the conclusion that article 20 of the New Family code cannot control this phenomenon of early marriage in Morocco.

The majority of the interviewees confirmed the increase in the number of underage married girls.

Thus, the number of marriage contracts registered in the Ministry of Justice and Liberty in Rabat raises from 18,341 in 2004 to 35,151 contracts of marriage in 2013.

It is also reported by the Court of the Family in Fez that :

Iin 2012 the number of girls asking for written justification for the authorization of underage marriage was 1432.In 2014, it raised to 1541. He noted that up to March 12, 2015 , they have registered 252.

It is further stated by the managing judicial deputy of the court of Fez that: 
...the percentage of early marriage in Fez is raised with $11 \%$ according to the statistics given by the Ministry of Justice and Freedom in 2013.

He added that:

...from all the demands presented to the judge only $10 \%$ are refused which are in most of the time justified by medical experts who confirm the physical inability of the young girl to assume marital responsibilities.

\section{The Low Income of Moroccan Families as a Significant Variable Responsible for the Increase of Underage Marriage}

It is commonly agreed that what is stated in the New Family code does not stand against the koranic percepts and the Sunah as the majority of the laws in the New Family law are based on Koran and the prophet's sayings. However, it is worth pointing out that the nature of the phenomenon of early marriage and its rise in Morocco is very complicated because of the interaction of the economic and socio-cultural and legal variables. It is stated by the majority of my interviewees that the low income of Moroccan families in rural areas and marginalized districts, which are mostly migrating from the countryside looking for a better life, is considered as a substantial reason behind the continuation of this phenomenon under study. It is among those families that early marriage is generally spread because parents usually find in this type of marriage an outlet to have one daughter less to take care of at the economical level. In rural areas and the marginalized urban district regions of the city of Fez, the extensive family is still a very frequent tradition. Most of the girls belong to families that have between 5 to 7 children.

A telling example worth pointing out from the sessions the author attended with the Family Affair Judge is the case of Fatima, 16 year old from the countryside of Tissa, around 30 miles away from Fez, who has never been to school and whose parents seem to pride themselves over their daughter who is going to marry to an owner of a big taxi considering this marriage as an outlet for their daughter from poverty and especially that the man is rich.

\section{The Dominance of Social Norms and Traditions Over the Law}

This rise in early marriage also goes back to the socio-cultural variable. As far as this factor is concerned, there seems to be a confusion between the norms, traditions, on the one hand, and the legitimate and legal rules, on the other hand. Many of the interviewees indicate that the continuation of this bad social practice is largely due to ignorance and illiteracy among Moroccan families as well as the rigid patriarchal mentality. However, some interviewees link this increase in the number of child marriage to the absence of a progressive vision to the Islamic Fiqh that primarily seeks to raise people's awareness of the real Islamic Laws as far as marriage is concerned. Thus, despite the many advocacy campaigns by the government, National and International campaigns and civil society that have carried out many projects for the sake of sensitizing people the Moroccan families' ignorance of the laws regulating marriage still exists. A good example to cite here is the Advocacy campaign help by ISIS Center for women and Development located in Fez and Vital Voices in Washington DC who worked on sensitizing Moroccan women throughout different regions (Fez, Sefrou, Middelt, Tetouane) about the danger of this social phenomenon on the girls "psychological, social and economic situation". The project lasted for a whole year (2011-2012). In this connection, one of the interviewees claimed come out with very interesting results that led to minimizing the number of early marriages in the surveyed areas (For more details see Nelson, 2012).

Coming back to the present study, it has been claimed by one of my interviewees that: 
This phenomenon of early marriage is much more common, if not, exclusively practiced among non-educated families especially in rural areas and the marginalized urban sectors whereby parents do not care about the laws and give them no significant importance in their life.

Likewise, what characterizes these regions is the dominance the religious beliefs that seem to strongly organize and regulate marriage and family relationships in Morocco. An illustrative example is karima, 16 years old, whose mother is a widow. Upon the judge's query concerning why she should marry her daughter to the first man asking for her hand while she can still have other better opportunities as she is still young. The mother responded saying:

I spend the whole day working in a snack bar in a marginalized district called Lmasiira, next to Bensouda, a very popular neighborhood.

She replied saying that:

It is better for Karima to get married, even underage, than earn her living by doing culturally stigmatized odd jobs that equally stand against our religion.

Many of the interviewees indicate that the continuation of this bad social practice is also largely due to ignorance and illiteracy among Moroccan families as well as the rigid patriarchal mentality. However, some interviewees link this increase in the number of child marriage to the absence of a progressive vision to the Islamic Fiqh that primarily seeks to raise people's awareness of the real Islamic Laws as far as marriage is concerned.

Thus, despite the many advocacy campaigns by the government and civil society that have carried out many projects for the sake of sensitizing people, the Moroccan families' ignorance of the laws regulating marriage still exists. In this connection, one of the interviewees claimed that:

This phenomenon of early marriage is much more common, if not, exclusively practiced among non-educated families especially in rural areas and the marginalized urban sectors whereby parents do not care about the laws and give them no significant importance in their life.

Therefore, the socio-cultural variables as well as the low level of education and the families' ignorance of the negative impact of early marriage on the physical, psychological and sociological levels are what contribute in the first place in the continuation of this social behavior.

What is most striking about all those young girls whom the author witnessed the judge interviewing during the two days sessions she attended with the Family Court Judge is that they see that the judge's attitudes are problematic for them as they seriously aspire to get married. While the judge kept asking whether they are convinced to get married and live with their mothers in law who equally have other unmarried children living with them, all of those would be young brides seem to agree to live with their family in-law and do the housework for the whole extended family. Sadiqi (2014) rightly noted that in rural areas there is no such degeneration of customs and mores as is the case in big cities. A further piece of evidence in support of what has been just stated by Sadiqi follows from my observations about another interviewee-Mariam who is 16 year old girl from the region of Taounate, 80 miles far away from Fez, who accepted to get married to a man who is 20 years older than her, and to whom she has never talked. The author was initially shocked by such a case, but she later on understand that by choosing this, the girl is symbolically preserving her family's reputation as she explicitly stated. 
Overall, it can be deduced that the socio-cultural constrains seem to threaten not only girls but parents as well, namely the stigma of never getting married if a girl is beyond 16, and the parents' fear of prostitution if their daughter is not married very young.

\section{Other Factors that May Encourage Child Marriage in Rural Areas}

Added to the above factors is the geographical variable. It is noticed that the majority of marriage proposals, which are presented to be authorized by the judge are below the age of 18 years, and the families live in the rural areas or in the marginalized districts of Fez. For example, during the author's attendance of the two day sessions with the Family Affairs Judge of marriage in Fez, among the 37 cases presented, she witnessed that $90 \%$ of them were from the rural areas. This fact is further consolidated by one interviewed lawyer who states:

During my five year experience as a lawyer, no single family from the urban area of Fez came to ask for permission to marry their daughter below the age of 18 .

Another instance is mentioned by judge who worked for several years in Fez and now moved to the region of Rachidiya, in the south of Morocco, who pointed out the following:

Besides the norms and traditions that seem to regulate the practices related to marriage among Moroccan families, which I agree that they vary from one region to another, the region of Fez is not that of Rachidiya, and even the physiological structure of a girl from Rachidiyya who is 16 year old is not the same as that of a girl of the same age living in Fez.

Therefore, the results reached pushed us to assume the validity of the two main hypotheses that we have stipulated at the outset of this paper. That is to say, despite the legal nature of the family code which limits the legal age of marriage into 18 years old, this law proves that it could not control this phenomenon. As to the second hypothesis, it is confirmed that the economic and the socio-cultural constraints contribute into the consolidation of the phenomenon of early marriage in the Moroccan society, viz., in rural areas, which makes this social behavior very hard to manipulate. All the evidence presented above proves the validity of this hypothesis.

Taking into account the nature of the phenomenon of early marriage which is very complex due to the intersection of a number of, economic, socio-cultural, legal and geographical variables such as the domination of poverty, low income of families, the low level of education, and the ignorance of the damage, this phenomenon can have on early married girls physically, psychologically, and socially. The geographical or spatial variable also proved to have a crucial role in this respect. These hypotheses were equally confirmed by the results of the ISIIS Center 2011-2012 in collaboration with Vital Voices Network in Washignton DC.

Indeed, a number of modifications in article 20 will undoubtedly help in diminishing the high rate of underage marriage. This has also been emphasized in an interesting work by Eliott (2009) in which she rightly contended that:

In order for the New family code to be fully implemented and gender equality to be instituted in all spheres of public and private life an all encompassing economic and educational reforms has to go hand in hand with social changes. (p. 37)

\section{Conclusion and Recommendations to Reduce Child Marriage}

It has been clearly demonstrated that a unilateral approach to this serious and complex problem is unlikely to succeed in reducing this social phenomenon. A legal approach that does not take into account, the economic 
and the socio-cultural perspective as well as the spatial/geographical dimension of the issue under study will not be able to provide a plausible solution. We need a global approach where each of the economic, social, cultural, legal and geographical variables are to be taken into account.

Therefore, from the interview sample, a number of recommendations to help minimize the number of young married girls have been drawn out and can be summarized as follows:

- Economic empowerment of families in those rural and marginalized urban district will highly contribute to reduce the rate of early marriage since the amelioration of the parents' situation will not make those underage married girls victims of poverty.

- To allow the marriage of girls at the age of 16 with a permission from the judge supported with a medical expertise proving that the girl is physically and psychologically apt to enter the institution of marriage.

- Education of both girls and boys and economic empowerment of girls in rural areas which will enable those girls of taking their own decisions and making the right choice at the appropriate age where the substantial requirements for entering the marital institution are satisfied.

- Organizing visits to those rural and very marginalized areas of Morocco where this bad social behavior is still considered the norm.

- Increasing the number of advocacy campaigns to sensitize Moroccan families as these campaigns proved to have had a lot of positive effects on families in the urban areas whereby the phenomenon has remarkably been reduced. High level government leaders should also be engaged to find solutions to diminish the negative effects of this pathological (abnormal) practice.

- Emphasizing on the role of women's and youth's organizations.

- Reconstruction of the representation of the Moroccan families of those stereotypes about this phenomenon of early marriage by virtue of its being a non-healthy legal and socio-cultural behavior.

- The interviewees equally recommend that the judges, lawyers should also rely on the help of the sociological research conducted about this issue of early marriage; in addition to organizing conferences concerned with the New Family Code.

\section{References}

Charrad, M. (2012). Family law reforms in the Arab world: Tunisia and Morocco. Proceedings from the Twentieth Anniversary of the International Year of the Family, 2014. University of Texas at Austin, Texas.

Ennaji, M. (2011). Women's NGOs and social change in Morocco. In F. Sadiqi, \& M. Ennaji (Eds.), Women in the Middle East and North Africa: Agents of change (pp. 79-88). London: Routledge.

Hanafi, L. (2013). The implemetation of Morocco's 2004 Family Code Moudawana: Stock Taking \& Recommendations. Retrieved from http://kvinfo.dk/sites/default/files/studymoudawana.pdf

Kerkech, R. (2013). Droits des femmes Méditerranéennes après les RevolutionsArabes (Mediterranean women' rights after the Arab revolutions). The ISIS Center for Women and Development, Palais Congres in Fez, Morocco.

Nelson, A. (2012). The journey through transition: Stories of women-led change in the Middle East and North Africa. Georgetown University School of Foreign Service in Qatar Auditorium, Education City, Doha.

Sadiqi, F. (2008). The central role of the family code in the Moroccan feminist movement. British Journal of Middle Eastern Studies, 35, 325-337.

Sadiqi, F., \& Ennaji, M. (2006). The feminization of public space: Women's activism, the family law, and social change in Morocco. Journal of Middle East Women's Studies, 2(2), 86-110.

Zvan Elliot, K. (2009). Reforming the Moroccan personal status code: A revolution for whom. Mediterranean Politics, 14(2), 213-227. 